\title{
Lipopolysaccharide Binding Protein, Cytokine Production in Whole Blood, and Lipoproteins in Cystic Fibrosis
}

\author{
SABINA SCHMITT-GROHÉ, VALERIE HIPPE, MICHAEL IGEL, KARL VON BERGMANN, \\ HEINZ G. POSSELT, ANDREAS KRAHL, CHRISTINA SMACZNY, THOMAS O.F. WAGNER, \\ WILFRIED NIKOLAZIK, RALF SCHUBERT, MICHAEL J. LENTZE, AND STEFAN ZIELEN \\ Children's Hospital Medical Center [S.S.-G., V.H., M.J.L.], Department of Clinical Pharmacology [M.I., \\ K.v.B.], University of Bonn, 53113 Bonn, Germany; Department of Pediatrics [H.G.P., A.K., R.S., S.Z.], \\ Pulmonary Department [C.S., T.O.F.W.], University Hospital of Frankfurt, 60590 Frankfurt, Germany; \\ Department of Pediatrics [W.N.], University Hospital, 45147 Essen, Germany
}

\begin{abstract}
According to the endotoxin lipoprotein hypothesis, lipoproteins may down-regulate cytokine production by neutralizing lipopolysaccharide (LPS) binding protein (LBP) complexes. We investigated the correlation between lipoproteins, LBP, cytokine production, and clinical status in Delta F 508 (homozygous) individuals. Cystic fibrosis patients with mild disease were compared with those with more severe disease and age-matched controls. LBP, IL-8, and tumor necrosis factor- $\alpha$, using a chemiluminescent immunometric assay, and fat intake, as well as serum triglycerides, cholesterol, very low density lipoprotein, LDL, and HDL were measured. In more severe disease there was a correlation between maximum expiratory flow at $25 \%$ of vital capacity and HDL. To adjust for the influence of colonization with Pseudomonas aeruginosa, those who were colonized with $P$. aeruginosa were analyzed separately. There was a significant correlation between LBP and forced expiratory volume in $1 \mathrm{~s}$. Lipoproteins may have a modulating effect in more advanced
\end{abstract}

\section{ABSTRACT}

disease and are not influenced by fat intake. LBP correlates those who were colonized with $P$. aeruginosa $(\mathrm{Psa}+)$ with clinical status as well as lung function and may be a critical molecule regulating LPS-induced inflammation. (Pediatr Res 58: 903907, 2005)

CF, cystic fibrosis

\section{Abbreviations}

CHOL, cholesterol

$\mathrm{CV}$, coefficient of variation

$\mathbf{F E V}_{1}$, forced expiratory volume in $1 \mathrm{~s}$

LPS, lipopolysaccharide

LBP, LPS binding protein

$\mathbf{M E F}_{25}$, maximum expiratory flow at $25 \%$ of vital capacity

Tlr4, Toll-like receptor

TG, triglycerides

TNF- $\alpha$, tumor necrosis factor- $\alpha$
Progressive pulmonary destruction is a major cause of mortality and morbidity in CF. The most important factor in the pathogenesis of lung disease in CF is a neutrophil-rich inflammation. The critical mediators for neutrophil influx in the lung are IL-8, TNF- $\alpha$, IL-1, complement-derived chemoattractants, and leukotriene $\mathrm{B}_{4}$. In addition, neutrophil elastase, LPS, and Pseudomonas aeruginosa antigens can all stimulate further IL-8 production to sustain the neutrophilic influx (1). Downregulation of inflammatory cytokine secretion, oxidative stress, and nutritional status may have an important impact on clinical course. Longitudinal follow-up shows that malnourished patients of all ages have significantly worse lung function than

Received November 12, 2004; accepted March 1, 2005.

Correspondence: Sabina Schmitt-Grohé, M.D., Children's Hospital Medical Center, University of Bonn, Adenauerallee 119, 53113 Bonn, Germany; e-mail: s.schmitt. grohe@uni-bonn.de

DOI: 10.1203/01.PDR.0000182598.98167.24 their normally nourished counterparts (2). In addition, previous studies (3-5) have shown that lipid metabolism is impaired in CF. In this regard, impaired lipoprotein metabolism might influence LPS-mediated chronic inflammation. Lipoproteins may down-regulate proinflammatory cytokines by neutralizing LPS. In vitro and animal studies have shown that CHOL- and TG-rich lipoproteins such as HDL (6), LDL (7), very LDL (VLDL) (8), and lipoprotein-(a) (9) bind and detoxify LPS. Unbound or not neutralized LPS by lipoproteins can be transferred via LBP to targets such as CD14 on cellular membranes inducing nuclear factor- $\kappa \mathrm{B}$-mediated synthesis of proinflammatory cytokines (10). In this regard, the high-affinity LBP/LPS complex potentiates the cellular response to LPS. The crucial role of LBP was shown in studies with mice rendered deficient in LBP by targeted gene inactivation. Mice deficient in LBP did not mount inflammatory responses to small amounts of LPS or bacteria and did not die when challenged with LPS (11). 
Revealing the nature and mechanism of LPS-induced inflammation might help us to understand and manage CF lung disease.

The aim of this study was to assess the correlation between lipoproteins, levels of LPS binding protein, as well ex vivo cytokine production and clinical status in CF patients with the Delta F 508 (homozygous) mutation.

\section{METHODS}

Subjects. Patients with the Delta F 508 (homozygous) mutation were recruited from the cystic fibrosis outpatient clinic of the Children's Hospital Medical Center at the University of Bonn and Essen, as well as from the Department of Pulmonary and Pediatrics of the University of Frankfurt. Healthy individuals served as controls. Exclusion criteria were clinical or laboratory signs (C-reactive protein $>20 \mathrm{mg} / \mathrm{L}$ ) of an exacerbation, treatment with systemic steroids $14 \mathrm{~d}$ preceding this trial, or participation in another study within the past $30 \mathrm{~d}$.

Patients characteristics. Forty-four patients (28 male and 16 female subjects) and 22 controls (14 male and 8 female subjects) were recruited for the study. Median age of patients was 13 y (range, 1-43 y) and median age of controls was 12.5 y (range, 1-40 y). Cytokine and lipoprotein data were available from all study subjects and controls (with the exception of lipoproteins in one control). Thirty-seven of the 44 patients were able to perform lung function testing. Microbiologic testing was performed in all study subjects. Twenty-five patients had microbiologic evidence of $P$. aeruginosa colonization. We grouped patients in clinically mild (71-100 points) and more severe disease (41-55 points) according to their Shwachman score (12). To adjust for sex and age, we matched patients and controls by sex and age $( \pm 2$ y). Details are shown in Table 1.

Spirometry. Lung function tests $\left(\mathrm{VC}, \mathrm{FEV}_{1}\right.$, and $\left.\mathrm{MEF}_{25}\right)$ were performed using a Master Screen Body (VIASYS, Wurzburg, Germany).

Cytokine assessment. Blood ( $9 \mathrm{~mL})$ was collected in endotoxin-free collection tubes (EDTA, Monovette, SARSTEDT, Nuembrecht, Germany).

$\boldsymbol{L B P}$. Whole blood was centrifuged at $1000 \times \mathrm{g}$ for $5 \mathrm{~min}$ at room temperature. The supernatant was removed and frozen immediately at $-20^{\circ} \mathrm{C}$ until assessment. LBP was measured using a chemiluminescent immunometric assay (DPC Biermann, Bad Nauheim, Germany). According to the manufacturer, this assay has a high intraassay precision for LBP (CV maximum 5.0\% at a mean concentration of $4.8 \mu \mathrm{g} / \mathrm{mL}$, minimum $3.1 \%$ at a mean concentration $26 \mu \mathrm{g} / \mathrm{mL}$ ), interassay precision (CV maximum $10.6 \%$ at a mean concentration of $4.8 \mu \mathrm{g} / \mathrm{mL}$, minimum $3.6 \%$ at a mean concentration $26 \mu \mathrm{g} / \mathrm{mL}$ ), $99.9 \%$ specificity, and a sensitivity of $0.2 \mu \mathrm{g} / \mathrm{mL}$ ).

IL-8 and TNF- $\alpha$. Fifty microliters whole blood was diluted with $500 \mu \mathrm{L}$ glutamine-enriched RPMI 1640 (Invitrogen, UK). The mixture was vortexed and incubated in an atmosphere of $95 \%$ humidified air, $5 \% \mathrm{CO}_{2}$ at $37^{\circ} \mathrm{C}$. The samples were harvested after $4 \mathrm{~h}$, vortexed again, and centrifuged at $1000 \times$ $g$ for $5 \mathrm{~min}$ at room temperature. To adjust for intraassay variance, each blood

Table 1. Patients Characteristics

\begin{tabular}{|c|c|c|c|}
\hline & \multicolumn{2}{|c|}{ CF patients } & \multirow[b]{2}{*}{$\begin{array}{l}\text { Controls } \\
(\mathrm{n}=22)\end{array}$} \\
\hline & $\begin{array}{c}\text { Mild } \\
\text { disease } \\
(\mathrm{n}=22)\end{array}$ & $\begin{array}{c}\text { More } \\
\text { severe } \\
\text { disease } \\
(\mathrm{n}=22)\end{array}$ & \\
\hline & \multicolumn{3}{|c|}{ Median (range) } \\
\hline Age (years) & 12.0 & 13.5 & 12.5 \\
\hline $\operatorname{Sex}(m / f)$ & $(14 / 8)$ & $(14 / 8)$ & $(14 / 8)$ \\
\hline Body mass index $\left(\mathrm{kg} / \mathrm{m}^{2}\right)$ & $19^{*}$ & $17 * \dagger$ & $21 * \dagger$ \\
\hline Fat intake $(\mathrm{g} / \mathrm{kg})$ & $1.88 \ddagger$ & $2.38 \ddagger \S$ & $1.28 \ddagger \S$ \\
\hline P. aeruginosa + & 9 & 16 & - \\
\hline Shwachman score & $85 \|$ & $55 \|$ & - \\
\hline $\mathrm{FEV}_{1}(\%$ predicted $)$ & 80II & 59II & - \\
\hline $\operatorname{IgG}(\mathrm{g} / \mathrm{L})$ & 11 & 12 & - \\
\hline
\end{tabular}

$\mathrm{m}$, male; f, female; $P$. aeruginosa + , Pseudomonas aeruginosa colonization; $\mathrm{FEV}_{1}(\%$ predicted $)$, forced expiratory volume in $1 \mathrm{~s}$ in $\%$ predicted; $\mathrm{IgG}(\mathrm{g} / \mathrm{L})$, Immunoglobulin $\mathrm{G}$ in gram per liter.

$* p<0.023, \dagger p<0.007, \ddagger p<0.007, \S p<0.002, \| p<0.0001$, I $p<$ 0.01 sample was run in three different tubes in parallel for each concentration. The supernatants of the three aliquots were mixed, frozen immediately, and stored at $-20^{\circ} \mathrm{C}$. The amount of IL- 8 and TNF- $\alpha$ was assessed using a chemiluminescent immunometric assay (DPC Biermann, Bad Nauheim, Germany). According to the manufacturer, this assay, for IL-8, has a high intraassay precision (CV of $3.7 \%$ ), interassay precision (CV of $7.4 \%), 100 \%$ specificity, and a sensitivity of $2 \mathrm{pg} / \mathrm{mL}$, and, for TNF- $\alpha$, intraassay precision $(\mathrm{CV}$ of $3.6 \%$ ), interassay precision (CV of $6.5 \%), 100 \%$ specificity, and a sensitivity of $1.7 \mathrm{pg} / \mathrm{mL}$.

Lipid and lipoprotein analyses. Blood $(10 \mathrm{~mL})$ was collected in collection tubes (Monovette, SARSTEDT, Nuembrecht, Germany) after a 12-h overnight fast. Serum was separated immediately by centrifugation at $3000 \times g$ for 10 min at room temperature. The concentrations of total $\mathrm{CHOL}$ and TG were determined enzymatically following a standard procedure: HDL was determined directly after precipitation of apolipoprotein B particles using dextran sulphate and PEG-modified esterase/oxidase (HDL-C + , Roche Diagnostics, Mannheim, Germany). LDL was calculated by the method of Friedewald (13).

Protocol. All subjects (with the exceptions of six children $<4$ y of age) performed spirometry, gave a blood sample, and provided a sputum sample (if this was not possible due to age, a deep pharyngeal swab was performed). Patients were asked to report their meals on a standardized food protocol for 1 wk. The protocol was approved by the ethics committee of the universities of Bonn, Essen, and Frankfurt. Informed consent was obtained from all patients' parents.

Data analysis. After grouping the individuals into one of three categoriesmild disease, more severe disease, and controls-Kruskal-Wallis analysis was applied to compare the three groups. We compared outcomes for two groups using the Mann-Whitney $U$ test. The correlations between quantitative data were estimated using Spearman correlation coefficient. A general linear model (GLM) was used to study the relationship between $P$. aeruginosa; clinical status; age; lung function $\left(\mathrm{FEV}_{1}, \mathrm{VC}, \mathrm{MEF}_{25}\right)$; total leucocyte, monocyte, and neutrophil count; and CHOL, HDL, LDL, VLDL, TG, and LBP levels. Only main effects were included in the first step. The model was reduced by excluding the factors with the highest $p$ values as long as they were above 0.1 . To check for interactions between the remaining variables, two-way interactions were included and then were excluded stepwise following the same strategy.

\section{RESULTS}

$\boldsymbol{L B P}$. There was a significant difference in LBP between those with mild disease, more severe disease, and controls (mean, 5.8, 7.2, and $4.6 \mu \mathrm{g} / \mathrm{mL}$, respectively).

$\boldsymbol{I L}-\boldsymbol{8}$. There was a significant difference between those with mild disease, more severe disease, and controls (mean, 22.4, 43.3 , and $10.7 \mathrm{pg} / \mathrm{mL}$, respectively).

$\boldsymbol{T N F}-\boldsymbol{\alpha}$. There was a significant difference between those with mild disease, more severe disease, and controls (mean, $48.2,57.9$, and $33.3 \mathrm{pg} / \mathrm{mL}$, respectively). Cytokine values are provided in Table 2 .

Fat intake. There was a significant difference between those with mild disease, more severe disease, and controls [mean (range), 2.26 (0.8-5.0), 3.05 (1.13-6.9), and 1.45 (0.74-2.89) $\mathrm{g} / \mathrm{kg}$, respectively].

Lipoprotein levels. Lipid concentrations in the different groups of subjects are given in Table 3. There was no significant difference in TG concentrations between those with mild

Table 2. Cytokines in patients and controls

\begin{tabular}{|c|c|c|c|}
\hline & \multicolumn{2}{|c|}{ CF patients } & \multirow[b]{2}{*}{ Controls } \\
\hline & Mild disease & More severe disease & \\
\hline & \multicolumn{3}{|c|}{ Median (range) } \\
\hline $\mathrm{LBP}(\mu \mathrm{g} / \mathrm{mL})$ & $4^{* \dagger}+(2-14)$ & $7 * \dagger+(1-15)$ & $4^{*}+(1-17)$ \\
\hline IL-8 (pg/mL) & $15 \S \|(3-100)$ & $25 \S \| \mathscr{I}(5-283)$ & 8§II (3-31) \\
\hline $\mathrm{TNF}-\alpha(\mathrm{pg} / \mathrm{mL})$ & $43 * * \circ(27-73)$ & $56^{* *}=(10-146)$ & $30^{* * 0}=(8-75)$ \\
\hline
\end{tabular}


Table 3. Serum lipoprotein concentrations in patients and controls

\begin{tabular}{|c|c|c|c|}
\hline & \multicolumn{2}{|c|}{ CF patients } & \multirow[b]{2}{*}{ Controls } \\
\hline & Mild disease & More severe disease & \\
\hline & \multicolumn{3}{|c|}{ Median mg/dl (range) } \\
\hline Cholesterol & $116^{*} \dagger(83-184)$ & $124 * \ddagger(85-191)$ & $168 * \dagger+(116-242)$ \\
\hline Triglycerides & $106(61-142)$ & $90(12-197)$ & $76(52-209)$ \\
\hline LDL & $52 \S \coprod$ I (18-96) & 56§凹 (33-89) & $91 \S \| \mathscr{I}(61-137)$ \\
\hline HDL & $44(36-85)$ & $46(22-73)$ & $55(36-101)$ \\
\hline
\end{tabular}

disease, more severe disease, and controls. However, there was a significant difference in total CHOL between those with mild disease, more severe disease, and controls.

In addition, for LDL there was also a significant difference between those with mild disease, more severe disease, and controls (Table 3). In contrast, no difference in HDL could be detected between the different groups of patients.

Cytokines and lipoproteins in relation to lung function. Lung function data are only analyzed as percentage predicted as younger children have smaller lung volume. There was only a slight but significant inverse correlation between $\mathrm{FEV}_{1}(\%)$ and the cytokines : IL-8 $(r=-0.459, p<0.004)$; LBP $(r=$ $-0.453, p<0.006)$; TNF- $\alpha(r=-0.342, p<0.038)$. There were similar findings for $\mathrm{MEF}_{25}$ and the following cytokines: IL-8 $(r=-0.473, p<0.003)$; LBP $(r=-0.472, p<0.004)$. There were no significant correlations between lipoproteins and cytokines as well as lipoproteins and lung function.

Influence of $\boldsymbol{P}$. aeruginosa. To adjust for the influence of colonization with $P$. aeruginosa, we analyzed those who were colonized with $P$. aeruginosa $(n=25)$ separately. Nine had mild and 16 moderate disease (see Table 1). There was a significant correlation between LBP and lung function parameters: $\mathrm{FEV}_{1}(r=-0.588, p<0.004)$ (see Fig. 1$)$ and $\mathrm{MEF}_{25}$ $(r=-0.575, p<0.005)$. There was only a slight but significant correlation between IL-8 and $\mathrm{FEV}_{1}(r=-0.466, p<$ $0.025)$, but there was a significant correlation between IL- 8 and $\mathrm{MEF}_{25}(r=-0.504, p<0.014$ ) (see Fig. 2). For TNF- $\alpha$, there was no significant correlation with lung function. There were no significant correlations between lipoproteins and cytokines or lipoproteins and lung function.

Moderate disease. As the metabolic interactions might have a different influence in more advanced disease states, we analyzed this subgroup separately. There was a significant inverse correlation between LBP and $\mathrm{FEV}_{1}(r=-0.561, p<$ $0.024)$ as well as $\mathrm{MEF}_{25}(r=-0.599, p<0.014)$ (see Fig. 3). For IL-8 and TNF- $\alpha$ there was no significant correlation with lung function. Moreover, there was a significant correlation between $\mathrm{MEF}_{25}$ and HDL $(r=0.555, p<0.021)$ (see Fig. 4). There were no significant correlations between the other lipoproteins and lung function or lipoproteins and cytokines.

General linear model. The results of the general linear model provide evidence that there is an interaction between LBP and IL-8.

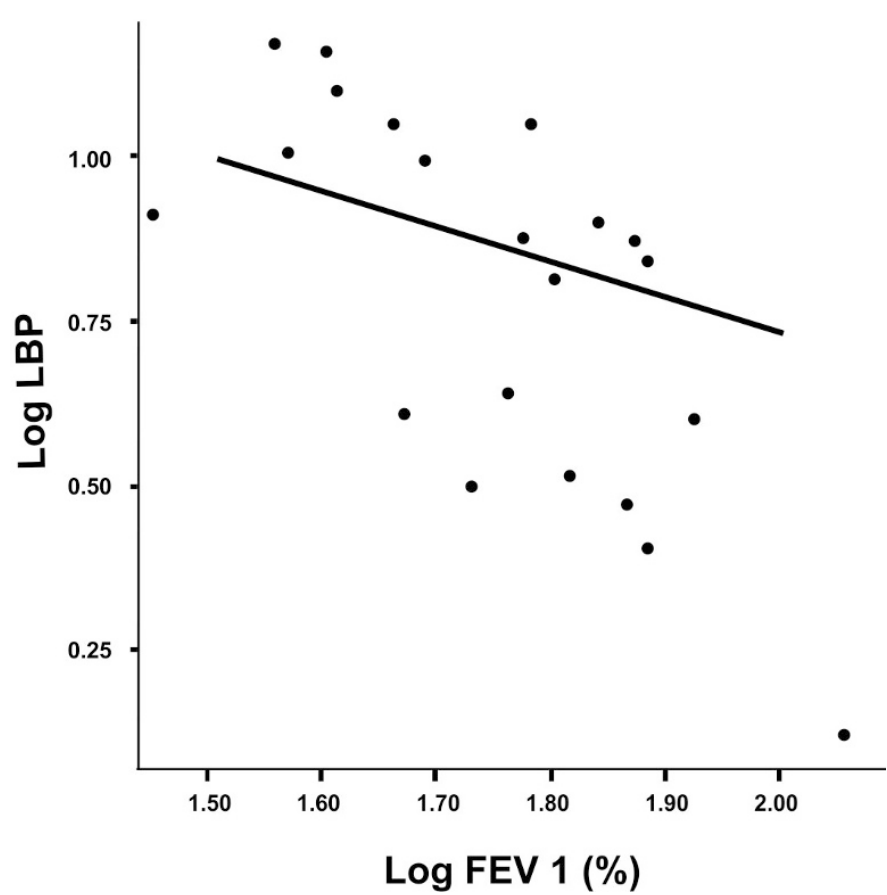

Figure 1. Log $10 \mathrm{LBP}$ in $P$. aeruginosa-positive subjects, plotted as a function of $\log 10 \mathrm{FEV}_{1}(\%)$ with linear regression line $(r=-0.588, p<$ $0.004, n=22$ ).

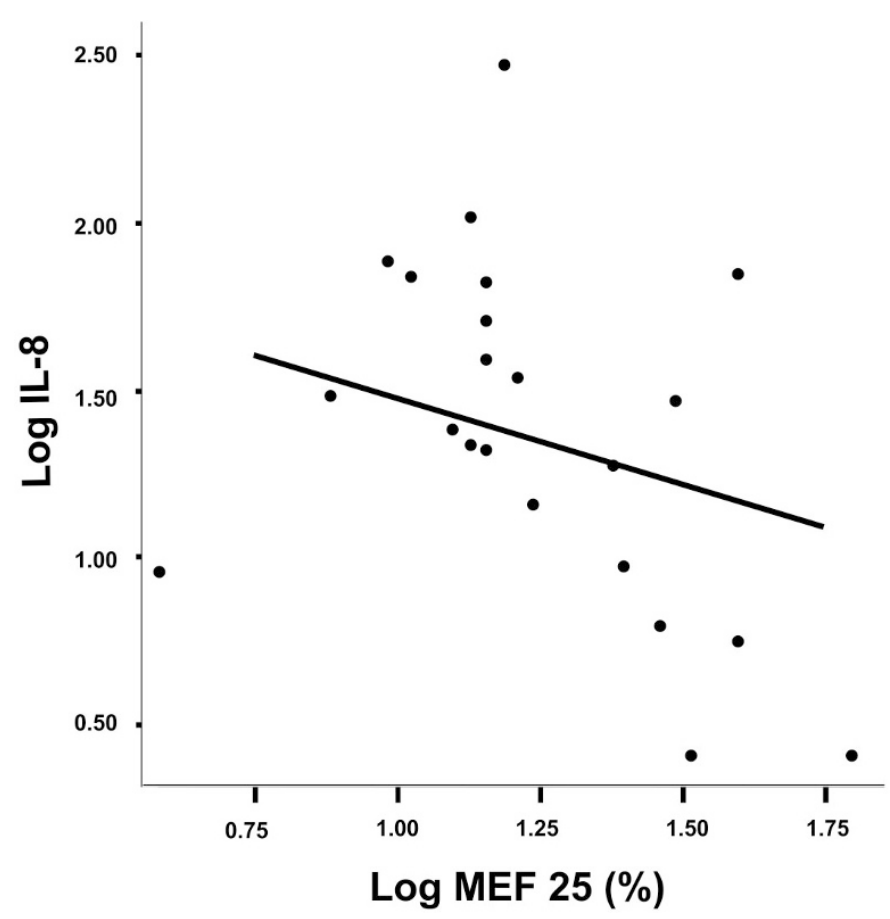

Figure 2. $\log 10 \mathrm{IL}-8$ in $P$. aeruginosa-positive subjects, plotted as a function of $\log 10 \mathrm{MEF}_{25}(\%)$ with linear regression line $(r=-0.504, p<$ $0.014), n=23$ ).

\section{DISCUSSION}

IL-8 in particular might contribute to progressive pulmonary inflammation by initiating and sustaining neutrophilic influx in CF lung disease. More interestingly, LBP is simultaneously induced and maybe an essential component of acute and chronic response to LPS. We found that LBP correlates with 


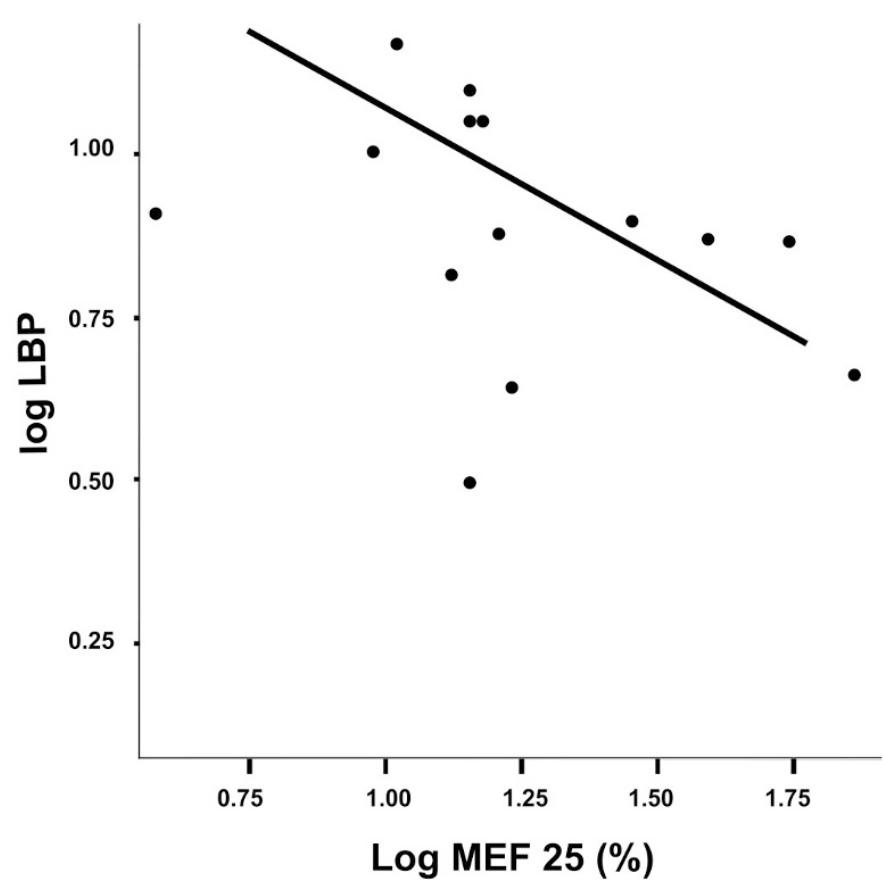

Figure 3. $\log 10 \mathrm{LBP}$ in more severe disease, plotted as a function of Log $10 \mathrm{MEF}_{25}(\%)$ with linear regression line $(r=-0.599, p<0.014, n=16)$.

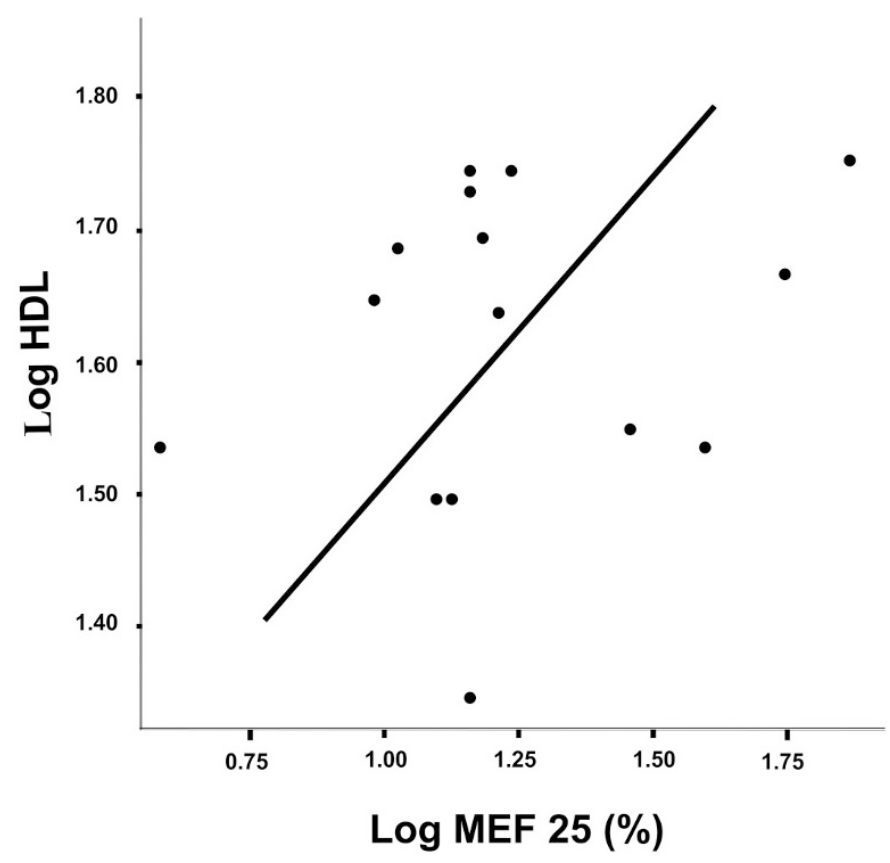

Figure 4. Log $10 \mathrm{HDL}$ in more severe disease, plotted as a function of Log $10 \mathrm{MEF}_{25}(\%)$ with linear regression line $(r=0.555, p<0.021, n=17)$.

clinical status as well as lung function in CF patients colonized with $P$. aeruginosa and may be a critical molecule regulating LPS-induced inflammation.

LBP levels are increased in stable chronic obstructive pulmonary disease (COPD) patients (14). To our knowledge, this is the first study to show that the same is true in stable CF patients. Moreover, we provided evidence of a negative correlation between plasma LBP levels and lung function in CF, respectively, controls and patients with mild disease had sim- ilar values. As a phospholipid transport protein, LBP is synthesized in the liver and facilitates the transport of LPS to HDL $(6,15)$. Bound to HDL, LPS is biologically inactive, providing a mechanism to both transport and detoxify bacterial LPS in plasma $(16,17)$. Thus, this mechanism might explain the protective effect of HDL but not the inverse relation of LBP and lung function. LBP correlated negatively with lung function in the overall $P$. aeruginosa-colonized group and in the smaller subgroup of more severe disease. (LBP data and lung function data were available in 22 of the $25 P$. aeruginosa-positive patients, but HDL and lung function data were only available in 17 of the 22 patients with more severe disease.) On the other hand, in those who were colonized with $P$. aeruginosa, there was no clinically significant correlation between lung function and lipoproteins. Therefore, it seems that LBP might be an important regulatory protein of disease severity in $\mathrm{CF}$, acting independently of lipoproteins. In addition, the general linear model provides evidence only of an interaction between IL-8 and LBP. Moreover, LBP (correlation LBP/FEV ${ }_{1}: r=-0.588$, $p<0.004)$ might be more sensitive and clinically important than IL-8 (correlation IL-8/FEV $1: r=-0.466, p<0.025$ ). There is a significant difference for LBP in those with more severe disease and milder illness. Patients with mild disease had similar values as controls. For IL-8, controls had lower values than those with mild disease, but the difference was not significant. Those with more severe clinical course had significantly higher values compared with those with mild disease (see Table 2). Moreover, the SD for LBP is 10 times less than it is for IL-8 ( $\sigma=45.8 / 3.4)$, indicating that LBP might be the more stabile marker. These differences might also be explained by the following: because LBP is synthesized in the liver and there is no ex vivo production, whereas IL-8 can still be generated in whole blood by PMN and macrophages.

The pros and cons of measuring cytokines in whole blood in a disease, the prognosis of which is determined by pulmonary inflammation, have been discussed previously by us (18). Meanwhile, interesting data emphasizing the importance of hematopoietic cells on LPS effects in the lung was published (19). Hollingworth et al. (19) tried to discern the role of hematopoietic cells and structural lung cells in mediating the movement of PMN into the airspace in response to LPS inhalation in Tlr4-/- knockout mice. Following inhalation challenge with LPS, wild-type animals demonstrated a robust inflammatory response, whereas Tlr4-/- knockout mice were unable to recruit PMN in the airspace. PMN recruitment to the airspace was completely restored in animals expressing Tlr4 solely on hematopoietic cells but not in those expressing Tlr4 exclusively on structural lung cells. Thus, there is a definite role of hematopoietic cells in LPS-induced pulmonary inflammation, at least in mice. The negative correlation between blood-derived cytokines and lung function in this study supports the idea that hematopoietic cells do contribute significantly to CF lung disease.

If there is an impact of LBP on clinical course, independent of lipoproteins, do lipoproteins influence disease severity in CF at all? We were able to show in a subgroup of more severely affected CF patients that lung function correlated inversely with HDL. This might give the idea that HDL has a protective 
effect on preservation of lung function, favoring the idea of a modulating effect of serum lipoproteins on inflammatory immune function. Interestingly, LDL and cholesterin values in CF patients, regardless of clinical status, were significantly lower than in controls. Significantly lower LDL and cholesterin levels in CF patients were also reported by Levy et al. (20). In our cohort, patients had lower HDL levels than controls, but in opposition to the results of Levy and co-workers, this difference did not reach statistical significance. We observed higher TG levels than in controls, but, in opposition to their study, this difference did not reach statistical significance. Moreover, we could not provide evidence of a positive correlation between TNF- $\alpha$ and TG. The differences between the studies are difficult to explain but may be related to cohort size $(n=31$ versus 44), genotype, and difference in inflammatory state.

So summarizing these results on lipoproteins, one could argue that the differences between $\mathrm{CF}$ patients and controls would reflect differences in fat intake and absorption. Interestingly it is exactly the opposite in terms of fat intake, CF patients had significantly higher fat intake than controls (median $1.99 / 1.28 \mathrm{~g} / \mathrm{kg}, p<0.003$ ) and those with more severe disease had a significantly higher fat intake (s. Table 1) than those with mild disease. But lipase intake was similar in both groups. Given that a high fat intake and a low body mass index (BMI) might reflect a bad fat absorption, our data confirm indirectly the results of Gaskin et al. (21) of a better prognosis in those without steatorrhea. Lipoprotein levels were not influenced by clinical status and fat intake. It could be that hepatic cholesterol synthesis is dysregulated in CF. So an endogenous mechanism is responsible for significantly lower LDL and $\mathrm{CHOL}$ levels in CF regardless of exogenous uptake. Moreover, as with essential fatty acids (22), which are also not affected by fat absorption, it might be a matter of $\mathrm{CF}$ transmembrane regulator dysfunction.

In summary, LBP is one of the critical molecules regulating the inflammatory response to LPS and correlates negatively with clinical status and lung function in homozygous Delta $\mathrm{F}$ 508 cystic fibrosis patients. Lipoproteins may have a modulating effect in more advanced disease states of CF but do not influence cytokine production in whole blood directly. Among CF patients, lipoprotein levels are not affected by fat intake.

\section{REFERENCES}

1. Chmiel JF, Berger M, Konstan MW 2002 The role of inflammation in the pathophysiology of CF lung disease. Clin Rev Allergy Immunol 23:5-27
2. Steinkamp G, Wiedemann B 2002 Relationship between nutritional status and lung function in cystic fibrosis: cross sectional and longitudinal analyses from the German CF quality assurance (CFQA) project. Thorax 57:596-601

3. Farrell PM, Mischler EH, Engle MJ, Brown DJ, Lau SM 1985 Fatty acid abnormalities in cystic fibrosis. Pediatr Res 19:104-109

4. Hubbard VS, Dunn GD, di Sant'Agnese PA 1977 Abnormal fatty acid composition of plasma-lipids in cystic fibrosis. A primary and secondary defect? Lancet 2:13021304

5. Lloyd-Still JD, Johnson SB, Holman RT 1981 Essential fatty acid status in cystic fibrosis and the effects of safflower oil supplementation. Am J Clin Nutr 34:1-7

6. Wurfel MM, Wright SD 1997 Lipopolysaccharide-binding protein and soluble CD14 transfer lipopolysaccharide to phospholipid bilayers: preferential interaction with particular classes of lipid. J Immunol 158:3925-3934

7. Flegel WA, Baumstark MW, Weinstock C, Berg A, Northoff H 1993 Prevention of endotoxin-induced monokine release by human low- and high-density lipoproteins and by apolipoprotein A-I. Infect Immun 61:5140-5146

8. Harris HW, Grunfeld C, Feingold KR, Rapp JH 1990 Human very low density lipoproteins and chylomicrons can protect against endotoxin-induced death in mice. J Clin Invest 86:696-702

9. Netea MG, de Bont N, Demacker PN, Kullberg BJ, Jacobs LE, Verver-Jansen TJ, Stalenhoef AF, Van der Meer JW 1998 Lipoprotein (a) inhibits lipopolysaccharideinduced tumor necrosis alpha production by human mononuclear cells. Infect Immun 66:2365-2367

10. Martin TR 2000 Recognition of bacterial endotoxin in the lungs. Am J Respir Cell Mol Biol 23:128-132

11. Jack RS, Fan X, Bernheiden M, Rune G, Ehlers M, Weber A, Kirsch G, Mentel R, Furll B, Freudenberg M, Schmitz G, Stelter F, Schutt C 1997 Lipopolysaccharidebinding protein is required to combat a murine Gram-negative bacterial infection. Nature 3899:742-745

12. Shwachman H, Kulczycki LL 1958 Long-term study of one hundred five patients with cystic fibrosis; studies made over a five- to fourteen-year period. Am J Dis Child 96:6-15

13. Friedewald WT, Levy RI, Fredrickson DS 1972 Estimation of the concentration of low-density lipoprotein CHOL in plasma, without use of the preparative ultracentrifuge. Clin Chem 18:499-502

14. Dentener MA, Creutzberg EC, Schols AM, Mantovani A, van't Veer C, Buurman WA, Wouters EF 2001 Systemic anti-inflammatory mediators in COPD: increase in soluble interleukin 1 receptor II during treatment of exacerbations. Thorax 56:721-726

15. Wurfel MM, Kunitake ST, Lichenstein H, Kane JP, Wright SD 1994 Lipopolysaccharide (LPS)-binding protein is carried on lipoproteins and acts a cofactor in the neutralization of LPS. J Exp Med 180:1025-1035

16. Ulevitch RJ, Johnnston AR, Weinstein DB 1981 New function for high density lipoproteins. Isolation and characterization of a bacterial lipopolysaccharide-high density lipoprotein complex formed in rabbit plasma. J Clin Invest 67:827-837

17. Baumberger C, Ulevitch RJ, Dayer JM 1991 Modulation of endotoxic activity of lipopolysaccharide by high density lipoprotein. Pathobiology 59:378-383

18. Schmitt-Grohé S, Naujoks C, Bargon J, Wagner TO, Schubert R, Hippe V, Zielen S 2005 Interleukin-8 in whole blood and clinical status in cystic fibrosis. Cytokine 29:18-23

19. Hollingworth JW, Chen BJ, Brass DM, Berman KG, Cook DN, Schwartz DA 2004 Hematopoetic expression of TLR4 is sufficient for neutrophil recruitment to the airspace following inhalation of lipopolysaccharide. Am J Respir Crit Care Med 169(7):A559

20. Levy E, Gurbindo C, Lacaille F, Paradis K, Thibault L, Seidman E 1993 Circulating tumor necrosis factor- $\alpha$ levels and lipid abnormalities in patients with cystic fibrosis. Pediatr Res 34:162-166

21. Gaskin K, Gurwitz D, Durie P, Corey M, Levison H, Forstner G 1982 Improved respiratory prognosis in patients with cystic fibrosis with normal fat absorption. J Pediatr 100:857-862

22. Freedman SD, Blanco PG, Zaman MM, Shea JC, Ollero M, Hopper IK, Weed DA, Gelrud A, Regan MM, Laposata M, Alvarez JG, O'Sullivan BP 2004 Association of cystic fibrosis with abnormalities in fatty acid metabolism. N Engl J Med 350:560-569 